\title{
Customer Relationship Management in Industrial Bank
}

\author{
Dileep Kumar*, M., Shanthimogaraj \\ Othman Yeop Abdullah Graduate School of Business, Universiti Utara Malaysia \\ *dileep@uum.edu.my
}

\begin{abstract}
Banking sector is in the midst of acute competion at national and international level. The way banks entertain and maintain their customers that determins its future business opportunities and development. Inorder to maintain the customers, employees working in banking sector need to be well equipeed with adequate skills in relationship marketing. A case study has been conducted in one of the Malaysian Bank* (name changed) inorder to asertain the significance of Customer Relationship Management. Lessons about the importance of employees' in the the implementation of Customer Relationship Management (CRM) is well established though this case study. This case study is an eye opener to the management and leaders of banking sector, inorder to have effective empoloyee engagement and development.
\end{abstract}

Keyword: Customer Relationship Management (CRM), Banking sector, Employees

\section{Introduction}

There has been a paradigm shift in the banking sector worldwide. Previously, banks dominated markets when they were able to offer new products and services that met customer needs. However, competitors were quick to imitate products and offer aggressive rates thus making this strategy unsustainable due to the decrease in the margin spread. Thus, there has been a movement from a transactional based approach adopted by the banks to a more relational based approach (Gummesson,1999; Gronroos, 1994; Morgan and Hunt, 1994; Peppers et.al., 1999; Boulding et.al., 2005; Frow and Payne, 2009; Bull and Adam,2011 as cited in Nguyen and Mutum, 2012). Banks have realised that customers are their most valuable asset and the relationship is mutually beneficial (Granroos,1994 cited in Plakoyiannaki and Saren, 2006) and needs to be maintained. Banks need to understand the demand of customers and fulfil the satisfaction of the customers as losing a customer is at the expense of the bank. Competitors are on the prowl for opportunities to grab customers from their competitors. This intense competition has forced banks to shift their resources from product/service-oriented strategy to customer-oriented services such as adoption of Customer Relationship Management (CRM) relying on IT (Bahardwaj et al.,1993; Pan et al., 2006; Peppard, 2000; Reinartz et.al., Rigby and Ledingham, 2004; Xu et.al.,2002 as cited in Shahraki, Kaveh and Khaniki, 2012). CRM is a process of value creation thought the creation and maintenance of relationship with consumers (Srivastara et.al.,1990 cited in Plakoyiannaki and Saren, 2006). This case study looks at the implementation of Customer Relationship Management in Industrial Bank and the level of adoption among employees which is the heart of the implementation process of CRM. Focus would be on why there is low adoption among employees and thus lack of success in the implementation of customer relationship management in Industrial Bank.

Description of the company: Industrial Bank Group is the leading financial service provider in Malaysia with a strong presence in South East Asia and it caters to the needs of consumer, investors, entrepreneurs, cooperation and non-profit organization. Currently, it has the largest network among Malaysian banks with over 2,100 branches, employs 42,000 employees and serves over 21 million customers in 17 countries. Industrial Bank has the largest asset base of more than USD135 billion and market capitalization of USD 22.0 billionwith total equity and total net profit of USD10.8 billion and USD1.5 billion respectively. It has adopted a conservative capital management approach while focusing on growth opportunities. Industrial Bank Islamic established in 2008 and is the largest Islamic financial player in Asia Pacific Region with $20 \%$ of the market share (as at Sept 2011) (Industrial Bank Annual Report 2011). After serving for half a century as the leading financial services key player in Malaysia, Industrial Bank in 2010 reframed its mission and strategic aspiration to accelerate its strategic transformation journey across the Industrial Bank Group within 5 years. Its new vision is to be the undisputed regional financial service leader within 2015 while the mission is to humanize financial services from the Heart of ASEAN. Based on this aspiration, Industrial Bank realigned its organization structure into three business pillars under the new "House of Industrial Bank" namely global wholesale 
serving the corporate commercial and non-retail banking segments, consumer financial services focusing on retail financial services from small and medium enterprises and consumers portfolio, insurance and Takaful. The new structure supports greater cross-border cooperation and would result in better innovative cross-selling and product bundling of services and products. In 2007, Industrial Bank implemented Customer Relationship Management technology in its Consumer Financial Services pillar with the support of Teradata, a service provider. A department was formed to specifically look into the settingup of the structure and emphasis was into the adoption of the technology as well as the processes that it had to emplace to roll out this model.There was not much priority given to the people aspect as Management expected the system to complement their job.

\section{Literature Review}

CRM is a integration of cross functionally between people, process and technology in its strategic approach to understand the organization's customer's, increase stakeholders' value and building long term relationship and profitability with the customers (Almotairi, 2009). According to Srivastave (as cited in Plakoyiannaki and Saren, 2006), CRM involves all aspects "identifying the customers, creating knowledge, building customer relationship and shaping their perception about the organization and its products". Gaining sustainable competitive advantage via Customer Relationship Management has become one of the strategic weapons for a modern service firm (Zeithaml, Parasuraman \& Malhotra, 2000). Involvement and buy-in of human resource of the company for implementation of CRM is critical (Bendapudi and Leone, 2002: Kohli et.al; 2001: Winer, 2001 as cited in Shahrakl, Kaveh and Khaniki, 2012). The success of service providers among others relies on the quality of relationship with the customers (Panda, 2003). Brown (2000) states that CRM is a process of acquiring, retaining and growing profitable customers and business strategies that aims to understand, anticipate and manage the needs of customers. Parvatiyar and Sheth (2001) defined CRM as "comprehensive strategy and process of acquiring, retaining and partnering with selective customers to create superior value for the company and the customer". Rootman et al. (2008) tried to identify the independent variables relating to the acceptance of bank employees which may have had an impact of the effectiveness of customer relationship management strategies in the South African banks. The three variables studied were the attitude, knowledge ability and two-way communication of the employees. The empirical study results clearly indicated that engagement of employees i.e. knowledge and attitude especially of customer facing employees were very important in maintaining the long term relationship with customers but no significant relationship between two way communication and effectiveness of the CRM strategies. Shahrakl, Kaveh and Khaniki (2012) conducted a study on Cooperative Development Bank. The findings clearly indicted that dependency on technology alone was not a guarantee for success of CRM. The ability of the bank to integrate its technology, process and individuals is significant to the success of the CRM implementation in the bank. This finding is also supported by Ravichandan and Lertwongste (2005). Shum, Bove \& Auh (2008) conducted a study on 3 banks which approached their CRM project differently. Two of the banks were less successful than their competitor bank on the CRM implementation due to less emphasis placed on managing employees and people. Only one of the banks spent more on change management and addressed organizational factors critical for the business or model. By providing the necessary change management, the buy in from employees were stronger and the overall performance was improving. Investment should be made in to provide "soft selling skills" such as training, team building and cultivating culture among the employees both before and after the implementation of CRM.

Studies conducted Nguyen, Sherif and Newby (2007), indicated that early failures in CRM was contributed by lack of management support, alignment of processes and focus on business strategies at high level. Studies conducted by various other researchers also indicated that CRM failures was contributed by several factors such as thinking of CRM on a purely technology driven activity, lack of management support, lack of customer centric culture, lack of involvement of various parties and lack of CRM skills (Kale.2004;Chalmeta.R., 2006 cited in Almotairi, 2009). In a presentation paper by Palmer (Jeannotte and Williams, 2003), culture is also used to describe the characteristics of the people in the various department within an organization. The culture difference is due to the background, education level, working experience and this can cause friction among the employees in the organization due to their perception and behaviour. Business units may feel that IT does not understand their business model, thus enable to resolve their issues while the IT may have perceive that business units do not have adequate knowledge on technology and how it can assist them to run their business (Limsarun et al., 2010). A study conducted by Peppard and Ward (1999) on 3 organization, clearly indicated that there was a gap or disconnection between the various business units and the IT. The variance can also be seen among high 
performance IT organization and low performance IT organization, business units and IT units and even business management and IT management. IT management felt the commitment by the business units were lacking as they were unable to provide specific requirements for technology and occurrence of frequent changes in specification while the business units were critical of the data generated and were dissatisfied on money spent on the technology that was not assisting their job functions (Peppard and Ward, 1999). In a study conducted by Eid (2007) among 159 banks that included local banks, foreign banks and joint banks that implemented the CRM system for at least a year indicated that the success of the CRM practise was depended on the individual employee who were the building blocks of customer relationship. The successful factors were categorised into 3 i.e. strategic level, tactical level and operational factors. He further added that CRM implementation required changes in the organizational culture at the strategic level (Eid, 2007). The critical role in successful implementation of the CRM system at the tactical level were the employee's acceptance level, integration of other systems, CRM software selection and training and updating employees on CRM system while at the operational level, a realistic implementation schedule, enterprise performance metrics for CRM and customer orientation, data mining and personalization (Eid, 2007). The finding is supported by the study on Customer Relationship Management practise of senior managers in 342 firms in U.S conducted by Lassar et al. (2008).The study recommended that organizational structure, supplemented with incentives and accountability were critical factors in obtaining strong performance and this was followed by organizational culture that is focussed on developing and sustaining customer relationship. (Lasser et al., 2008). In another study conducted by Dorhan (2010) at Kelly hotel indicated that employing managerial support such as motivation, empowerment and role modelling are paramount in encouraging employees to be committed to contributing to the success of the Irish hotel. Hence, based on the literature review, this study aims to explore the influence of employees on the implementation of Customer Relationship Management in Maybank.

\section{Failure of CRM}

The failure of CRM has been widely researched by many researchers. There are many causes of failure in CRM implementation whereby some of the causes may be inevitable while others could have been avoided by looking at a holistic approach before implementing the CRM technology. Employees play a significant role in ensuring the success of the CRM as they are handling the various areas of the CRM implementation i.e. development stage, data analysis, carrying out campaigns and interaction with the customers. The Internal Customer Satisfaction Survey (ICES) which was conducted by Towers Watson and then Tower Perrins on a yearly basis indicated that the result for Corporate Development Department which handles the implementation of Customer Relationship Management in Community Financial Services had been on a declining trend since 2010. In 2009, the CRM Department's ICES scoring was 55\% and in 2010 and 2011 it further declined to $48 \%$ and then $28 \%$ respectively. Based on the analysis of the questionnaires that were sent out to the various employees in the bank such as Customer Sales Executives, Branch Managers, Assistant Brach Managers, Financial Executives and the various business units indicated that the users were not satisfied with the services rendered by the CRM department. Key areas of dissatisfaction were from the communication aspect, the training conducted and the support rendered from the team. In comparison to other departments' scores, the CRM department which had been churning profit to the overall Community Financial services department since the implementation of the CRM technology scored the lowest results in 2011. There are only a limited number of research studies being conducted on the critical employee success factor in the implementation of CRM in the banking industry i.e. Eid (2007) and Shahrakl, Kaveh and Khaniki (2012). Moreover, most of the studies were conducted overseas and there is a need to explore if the employee factor is applicable in the banking industry in Malaysia namely Industrial Bank which is still in the infancy of adoption of CRM.

Statement of the problem: Industrial Bank has invested vast amount of money into the implementation of CRM technology to improve profitability of the bank via excellent and efficient customer service. Many campaigns and initiatives were rolled out using CRM to target the customers. However, from the 1000 leads sent to the branches nationwide on an average per day, only $10 \%$ of the leads are being action on by the employees. The average campaign conversion rate jumped from a low of $0.3 \%$ in 2007 to an average of $8 \%$ and to a high of $30 \%$ (Teradata Magazine Online 2011). The conversion rate is still not satisfactory as the CRM campaigns are now more refined and focused on target segments. Thus, comes a need for the management to look into the reason for the low adoption of CRM among employees as the business process and technology are emplaced. Among the reason for the low adoption of CRM by employees skills 
and behaviour, lack of communication, top Management support and knowledge management or training. Based on the findings of the performance and ICES scoring, the bank has designed some short and long term initiatives to address these gaps.

\section{Results}

Top Management Support: Many Branch Managers were not supporting the CRM initiatives as they were used to the old style of marketing which involved face to face relationship, thus they were not pushing their branches to action on the leads allocated to them. Some of the Branch Managers did not even ensure that their employees acted on the leads provided by CRM and some did not even know how to get the customer's profile from the leads given. Managers have to be the walking advertisement and promoting the CRM culture among his subordinates and pushing the various business lines to work together. By understanding the importance and the objective of the implementation of adoption, he can become an advocate and encourage his employees towards the usage of the leads( Soeini, Jafari \& Abdollahzadeh, 2012). Top management needs to support the relationship between the various business units which was not aligned due to lack of involvement at the various stages of CRM development Most of the decision on the implementation of CRM was discussed among the top level management i.e. IT management and Business units while the users were the front end users.

Employees skills and behaviours: The Consumer Sales Executive who sell consumer products (Mortgage Loans, Personal loans, Hire Purchase loans) and the Financial Executives who sell insurance normally conduct face to face transactions with their customers. They are able to interact with the customers and thus able to clarify issue and conduct sales. However, they are not comfortable and do not have the relevant skills to conduct telephone conversation with customers or strike a conversation to offer them products over the phone. Hence there is a process of organizational change. CRM project does not only include sales and marketing areas but also cross functional process (Rangarajan et al., as cited in Shum, Bove \& Auh, 2008). According to employee engagement study conducted by Konrad (cited in Droussiotis and Austion, 2006), employees are more committed when they have some control over the design and implementation of their work.

Training: Implementation of new technology and procedures to replace the legacy system can be quite chaotic to the users. During the implementation stage of the CRM in Industrial Bank, the end users were trained on the proper usage of the system. However, the product training and the system training was not synchronized in an orderly manner. In some states the product training was done earlier and then followed by the system and vice versa. The tenure between the training was also distant. Hence, many of the users did not fully understand the application of CRM. Extensive well organized training would assist the user to understand his function and role in achieving the organizational goals (Montes. et.al., 2003). Robey stated that training also assist employees to overcome barrier and as a result be more committed to change programs (as cited in Shum, Bove \& Auh (2006).Employees should also be given the competencies and confidence that their skills and existing knowledge has increased.

Communication: Prior to the development or design and planning stages of CRM, no communication was sent out to end users at branches and end user on the impending changes to be adopted. Only prior to the roll-out of CRM, was communication sent out to the various stakeholders. As the system change was a major change or the end user, their buy in and support should have been crafted. Communication was only sent out during the implementation stage of CRM. In his study Marks (2007), communication should be carried out at 3 phrases i.e. beginning-design state, during and after implementation of CRM and adoption stage at all hierarchical levels. According to him, at the design stage communication needs to be conducted from top to bottom inform them of the challenges currently being faced by the organization, changes that are being made and why they have to embrace changes in their job while at the second stage or implementation stage, the communication needs to be more aggressive and various channels of communication can be used i.e. email, video conferencing, teleconferencing, feedback session and causal conversation for better engagement. The final stage would involve communication among all the hierarchical levels so everyone understands the big picture and getting the goal achieved (Marks, 2007).

The scenario: The case study indicates employees are crucial for the implementation of the CRM in Industrial Bank as a successful implementation is based on three prong dependencies i.e. process, technology and people. Based on the case study conducted in Industrial Bank, 4 main elements that affected the low adoption among employees are employees' skills and behaviour, lack of communication, 
top Management support and knowledge management or training. As there a plans to further expand the usage of CRM to other business entities and also as part of the Regional expansion of Industrial Bank, it is necessary to find solution to address the gaps identified. Among the alternative solutions are:

Deployment or Roll-out in phases: The CRM which is a long term solution for an organization needs to to have a well designed deployment plan that can be done on staggered phases. Implementation which is carried out in well managed phases and small phases paves way for the employees to slowly adopt to the CRM solutions. The deployment can be carried out based on geographical areas, business units, locations or modules so as to allow the team to manage and address the gaps encountered by the employees and process. Efficient deployment of the CRM will encounter less resistance from the employees and success of the deployment in the short phases can be used to motivate adoption by more employees. Proper communication and success earned from each of the phases needs to be shares with the various stakeholders to get their buy-in on how the implementation at their entities can bring better benefits. The staggering out of the roll-out in phases can delay the total benefits reaped, it would be better in the long run as the concerns of the employees would be addressed suffieicntly.

Selection of employees and stakeholders for the team: The selection of the team to run the projects needs to come from the best employees from the various related business units that need to work together with the IT to design the implementation of the CRM model. The different line of business may have different preferences, culture or expectations on the system requirement and by roping them in from the initial stage of selection would be a good options as they can proactively participate and provide the relevant feedback and suggestions. Their expertise in the various fields will allow them to establish a consistent process which can predict the desired outcomes. Hence all the required stakeholders need to actively participate and they can cascade these changes among their business units to avoid conflicts at the deployment stage.

Single platform: The CRM system must be build to allow for integration of the various system i.e. accounting system, the legacy system in the organization and the business units system. Successful integration of system allows better database management and allow the flexibility for the expansion of the database should more stakeholders decide to ride on the existing platform. The 3 information types that needs to be embedded for effective CRM solution are descriptive, relationship and contextual data. The interaction provides a coherent picture of the customer's relationship with the bank. Seamless integration of system will allow flexibility in the sharing of business process and application among the various system. Easy updating of customer base can be executed. Moreover, an integrated system or a single platform allows for a 360 degree customer information view both for internal as well as the external data so that analysts can identify revenue opportunities, enhance sales channels, mitigate cost risks, leverage on valuable data and optimise contact management. End users need to be trained on the changes made to the system.

Careline or Helpdesk: Easy usage of the system will get employees buy in and they can promote the benefits of the integrated system to their peers. However, the CRM team needs to render assistance by setting up a careline or helpdesk to answer the various queries raised by the users. By promptly and professionally assisting them, the users would be more inclined to adopt to the changes. A booklet can be handed out to the end users on the frequently common raised issue and the solution to the problems for easy resolution of problems. This booklet can be updated when more and more business units participate in the CRM.

\section{Conclusion}

After four years of implementation of CRM, Industrial Bank has garnered lessons about the importance of employees to the implementation of Customer Relationship Management (CRM). Active and willing participation of employees at all levels with the proper process and technology in place can give it a competitive advantage as it would be able to do many activities such as cross sell, up sell, increase customer's profitability and customer retention with the banks. Successful implementation of CRM has allowed some banks to have a superior advantage over its competitors even at the initial implementation. However, the short coming earlier faced by Industrial Bank can be addressed with the proper governance, buy in from the relevant stakeholders, top management support, sufficient training, competency and channel readiness, incentive and compensation. 


\section{References}

Almotairi, M. (2009). A Framework For successful CRM Implementation. Paper presented at European and Mediterranean Conference on Information Systems.

Brown, S. A. (2000). Customer Relationship Management: A Strategic Imperative in the World of EBusiness. Canada: John Wiley \& Sons.

Drohan, R. (2010). Exploring the Nature of Effective Customer Relationship Management in the Irish Hotel Sector. Masters Thesis. Waterford Institute of Technology.

Droussiotis, A. \& Austin, J. ( 2006). Company practices of Cypriot firm : Perceptual differences between employers and employees . European Business review, 20(3), 208-221.

Eid, R. (2007). Towards a Successful CRM Implementation in Banks: An Intergrated Model. The Service Industries Journal, 27, 1021-1039.

Jeannotte, M. S. \& Williams, M. (2003). Creative Cities: The Role of Culture Presentation paper by Robert Palmer to the Department of Canadian Heritage.

Lassar, W. M., Lassar, S. S. \& Rauseo, N. A. (2008). Creating a Superior Customer-Relating Capability. MIT Sloan Management Review, Spring, 77.

Limsarun, T., Anurit, P., Chansa-Ngavej, C. \& Bunchapattanasakda, C. (2010). Does the Gap Matter?A study of IT and Business Culture Towards Customer relationship Management Practise. Research Journal of Social Science, 2(6),334-339.

Marks, M. L. (2007). A framework for facilitating adaptation to organizational Change Management. Journal of Organizational Change Management, 20(5), 732-739.

Montes, F. J. L., Jover, A. V. \& Fernandez, L. M. M. (2003). Factors affecting the relationship between total quality management and organizational performance. International Journal of Quality \& Reliability Management, 20(2/3), 188-208.

Nguyen, T., Sherif. J. \& Newby, M. (2007). Strategies for Successful CRM Implementation. Information Management \& Computer Security, 5(2).

Panda, T. K. (2003). Creating Customer Lifetime Value through Effective CRM in Financial Services Industry. Journal of Service Research, 2(2)

Parvatiyar, A. \& Sheth, J. N. (2001). Conceptual Framework of Customer Relationship Management, In J.N. Sheth, A.Parvatiyar, \&G.Shainesh (Eds.), Customer relationship management: Emerging concepts, tools and applications.New Delhi, Tata McGraw-Hill.

Peppard, J. \& Ward, J. ( 1999). Mind the Gap'diagnosing the relationship between IT organization and the rest of the business. Journal of Strategic Information Systems, 8, 29-60

Plakoyiannaki, E. \& Saren, M. (2006). Time and the customer relationship management process : conceptual and methodological insights. Journal of Business \& Industrial Marketing, 21(4), 218230.

Ravichandran, T. \& Lertwongsatien, C.(2005). Effect of information system resources and capabilities of firm performance. Journal of Marketing Research, 41(3), 293-305.

Rootman, C., Tait, M., \& Bosch, J. (2008). Variables influencing the customer relationship management of banks. Journal of Financial services Marketing, 13(1), 52-62.

Shahraki, A., Kaveh, F. \& khaniki, S. (2012). Integration of Resources and Capabilities to Implement CRM: Case of Cooperative Development Bank. Journal of Economics and Behavioural Studies, 4(4), 194203.

Shum, P., Bove, L. \& Auh, S. (2008). Employees' affective commitment to change: The key to successful CRM implementation. European Journal of Marketing, 42(11), 1346-1371.

Soeini, R. A., Jafari, B. \& Abdollahzadeh. (2012). CRM Performance Measurement Process. Int.Journal Emerging Science 2(1)134-148.

Teradata Magazine. (2011). Retrived on 11 March 2012 from http://www.teradatamagazine .com/v11n01/Features/Big-Data/.

Zeithaml, V. A., Parasuraman, A. \& Malhotra, A. (2000). Service Quality Delivery through Web Sites: A Critical Review of Extant Knowledge. Journal of Academy Marketing Science, 30(4), 362-75. 